\title{
Sex- and age-specific modulation of brain GABA levels in a mouse model of Alzheimer's disease
}

\author{
Upasana Roy $^{\text {a,b }}$, Lara Stute ${ }^{\text {b,c }}$, Corinna Höfling ${ }^{\text {c }}$, Maike Hartlage-Rübsamen ${ }^{\text {c }}$, \\ Jörg Matysik ${ }^{a}$, Steffen Roßner ${ }^{c}$, A. Alia ${ }^{b, d, *}$ \\ ${ }^{a}$ Institute of Analytical Chemistry, University of Leipzig, Leipzig, Germany \\ ${ }^{\mathrm{b}}$ Institute of Medical Physics and Biophysics, University of Leipzig, Leipzig, Germany \\ ${ }^{\mathrm{c}}$ Paul Flechsig Institute for Brain Research, University of Leipzig, Leipzig, Germany \\ ${ }^{\mathrm{d}}$ Leiden Institute of Chemistry, Leiden University, Leiden, the Netherlands
}

\section{A R T I C L E I N F O}

\section{Article history:}

Received 12 July 2017

Received in revised form 5 October 2017

Accepted 16 October 2017

Available online 26 October 2017

\section{Keywords:}

Alzheimer's disease

GABA

Sex difference

${ }^{1} \mathrm{H}$ high-resolution magic angle spinning

NMR

Longitudinal study

Tg2576 mouse model

\begin{abstract}
A B S T R A C T
Age and sex are risk factors of Alzheimer's disease (AD). Among the neurotransmitter systems, gammaaminobutyric acid (GABA) has been implicated in AD pathogenesis but the relevance of sex-specific GABAergic dysfunction during $A D$ progression remains unknown. In the present study, we utilized state-of-the-art high-resolution magic angle spinning nuclear magnetic resonance to systematically monitor the brain region-, age-, and sex-specific modulation of GABA levels in wild-type and Tg2576 mice with amyloid pathology. In addition, we followed the possible role of reactive astrocytes in sex-specific GABA modulation. In female Tg2576 mice, hippocampal GABA levels were significantly elevated, along with higher number of reactive astrocytes and amyloid deposition. The elevated GABA was found to be produced via the monoamine oxidase-B route from putrescine in reactive astrocytes, more substantially in female than male mice, thus suggesting a role of astrocytes in memory impairment and sex-related differences in AD. Our results paint a coherent model of memory impairment in AD and signify that dynamic changes in regional GABA may be at the root of marked sex disparities observed in AD.
\end{abstract}

(C) 2017 Elsevier Inc. All rights reserved.

\section{Introduction}

Alzheimer's disease is a progressive neurodegenerative disease characterized by impairment of memory and other cognitive functions. The pathological hallmarks of Alzheimer's disease include widespread neuronal degeneration and the formation of extracellular senile plaques and intracellular neurofibrillary tangles (Price et al., 1991; Terry et al., 1991). Synaptic dysfunction induced by $\beta$-amyloid $(A \beta)$ oligomer toxicity starts many years before the clinical onset of Alzheimer's disease and has been implicated in cognitive decline (Canter et al., 2016; Dulla et al., 2016).

Gamma-aminobutyric acid (GABA) is the major inhibitory neurotransmitter in the central nervous system (Li et al., 2016). Maintaining a proper dynamic balance between the excitatory glutamate (Glu) and inhibitory GABA neurotransmitters is critical

\footnotetext{
* Corresponding author at: Leiden Institute of Chemistry, Leiden University, Einsteinweg 55, 2333 CC Leiden, the Netherlands. Tel.: +31 715274623 ; fax: +31 71 5274600.

E-mail addresses: a.alia@chem.leidenuniv.nl, alia.aliamatysik@medizin.unileipzig.de (A. Alia).
}

for neuronal function (Lehmann et al., 2012). Altered synaptic balance was found to be one of the pathological factors that contribute to Alzheimer's disease (Canter et al., 2016; Dulla et al., 2016; Sun et al., 2009). Recent evidence indicates that a disrupted default neuronal network underlies impaired memory and that alterations of GABAergic circuits may contribute to Alzheimer's disease by disrupting the overall network function (Jucker and Walker, 2011; Li et al., 2016). Findings of GABAergic alterations in Alzheimer's disease are very conflicting. Early postmortem studies in human brain or in animal models have reported that GABAergic neurons and receptors are resistant to Alzheimer's disease pathology (Li et al., 2016; Lowe et al., 1988; Pike and Cotman, 1993; Rossor et al., 1982; Spillane et al., 1977). However, several recent publications demonstrate that GABAergic neurotransmission undergoes profound pathological changes in Alzheimer's disease (Ramos et al., 2006; Takahashi et al., 2010). In the temporal cortex of Alzheimer's disease patients, significantly lower levels of GABA were observed, indicating deficient synaptic function and neuronal transmission (Gueli and Taibi, 2013). The decreased GABA neurotransmitter levels were also observed in the cerebrospinal fluid of Alzheimer's disease patients and cognitively normal humans with aging 
(Bareggi et al., 1982; Grouselle et al., 1998; Zimmer et al., 1984). In contrast to these reports, elevated GABA levels in hippocampus and cerebrospinal fluid were reported in Alzheimer's disease patients and related to impaired synaptic plasticity, learning, and memory (Jo et al., 2014; Samakashvili et al., 2011). Therefore, a common agreement of GABA changes during Alzheimer's disease progression remains to be settled, before exploring drugs to target GABAergic neurotransmission as a potential therapy for Alzheimer's disease. The inconsistent and controversial results are likely attributed by differences in the timing and duration of experimental design, sex-specific and brain region-specific differences in GABA and complex pattern of GABA changes during aging. Many of the studies in animal models of Alzheimer's disease focused on predisease or early disease stages (Lalande et al., 2014; Nilsen et al., 2014a,b). However, systematic studies to follow changes in GABA during the entire spectrum of disease progression where sex and affected and unaffected brain region are taken into account are missing. The different brain regions such as cortex and hippocampus have heterogeneous structures and age-related changes in GABA content may occur at different rates in different areas with or without Alzheimer's disease (Davis et al., 1999). For example, GABAergic signaling dysfunction varies between hippocampus and prefrontal cortex during normal aging (McQuail et al., 2015). For this reason, the knowledge about the changes in the level of GABA during Alzheimer's disease progression in different brain region with age is necessary in order to establish the relevance of GABAergic dysfunctions in the pathology of Alzheimer's disease.

Emerging evidence suggests that Alzheimer's disease disproportionately affects women in both occurrence and severity (Carter et al., 2012; Musicco, 2009; Viña and Lloret, 2010; van Duijn et al., 2013). Sex differences in amyloid $\beta$ (A $\beta$ ) deposition in transgenic mice (Callahan et al., 2001; van Duijn et al., 2013) and humans (Corder et al., 2004) have been reported. The molecular mechanism accounting for sex-related differences in Alzheimer's disease remains unknown. In healthy human subjects, sex-specific differences in GABAergic markers have been reported (Cosgrove et al., 2007). It has been shown that healthy women have higher cortical GABA levels than men (Cosgrove et al., 2007; Sanacora et al., 1999). Up to now, no research is present in literature dealing whether and how sex and age may modulate the GABA levels in different brain regions during development of Alzheimer's disease pathology.

In this article, we present the first systematic longitudinal study to investigate the brain region-related and sex-related differences in GABA levels during development of disease in Tg2576 mice, a widely used model of Alzheimer's disease which mimics pathological aspects of Alzheimer's disease, including amyloid plaques, reactive astrocytes in the brain, and impaired spatial learning and memory (Hsiao et al., 1996; Kobayashi and Chen, 2005; Takeuchi et al., 2000). Our data demonstrate that age- and sex-related differences in GABA levels during Alzheimer's disease exist among brain regions, such as the hippocampus and the prefrontal cortex, important for learning, memory, and affection. Our results also indicate that regional differences in GABA could be at the root of marked sex disparities observed in incidence, manifestation, and prognosis of Alzheimer's disease.

\section{Materials and methods}

\subsection{Animals}

In this study, transgenic Tg2576 mice developed and described earlier (Hsiao et al., 1996) were used as model of Alzheimer's disease. The mice contain as transgene the human amyloid precursor protein (APP695) with the Swedish double mutation
(K670N, M671L) under control of a hamster prion protein promoter. Mice heterozygous for the transgene and wild-type (WT) littermates were on a C57BL/ $6 \times$ SJL background. Mice were housed in groups of 3-5 animals per cage and separated by sex, with ad libitum access to water and food at $23^{\circ} \mathrm{C}$ with 12 -hour day/12-hour night cycles. The cages contained red plastic houses (Techniplast) and shredded paper flakes to allow nest building. At the age of 4 weeks, transgenicity of the animals was tested by polymerase chain reaction of tail DNA as described elsewhere (Hsiao et al., 1996). Mice of both sexes were studied at the ages of 3, 6, 9, 12, and 18 months. Age-matched nontransgenic littermates served as controls. For high-resolution magic angle spinning nuclear magnetic resonance (HR-MAS NMR) as well as for histological studies, 6 female and 6 male animals were used per age group. All animal experiments were approved by the institutional animal care and animal use committee in accordance with the NIH Guide for the Care and Use of Laboratory Animals.

\subsection{Brain preparation}

Mice were sacrificed by $\mathrm{CO}_{2}$ inhalation, and brains were quickly removed. Prefrontal cortex, parietal cortex, hippocampus, and thalamus were carefully prepared and rapidly frozen by immersing in liquid nitrogen and subsequently stored at $-80^{\circ} \mathrm{C}$. For monoamine oxidase-B (MaOB), enzymatic assay entire hippocampus was used. For HR-MAS NMR studies, the individual brain regions were inserted into a $4 \mathrm{~mm}$ zirconium oxide rotor. $10 \mu \mathrm{L}$ of deuterated phosphate buffer containing $0.1 \% \quad(\mathrm{w} / \mathrm{v})$ 3-trimethylsilyl2,2,3,3-tetradeuteropropionic acid (TSP) was added as an NMR reference. The rotor was placed immediately inside the NMR spectrometer.

For histological studies, mice were sacrificed by $\mathrm{CO}_{2}$ inhalation and transcardially perfused with phosphate-buffered saline $(\mathrm{pH}$ 7.4) followed by $4 \%$ buffered paraformaldehyde through the left cardiac ventricle. After perfusion fixation, the brain was dissected out and placed in the same fixative for 24 hours at $4{ }^{\circ} \mathrm{C}$. After cryoprotection in $30 \%$ sucrose in $0.1 \mathrm{M}$ phosphate buffer for 3 days, the brains were snap-frozen in n-hexane at $-68{ }^{\circ} \mathrm{C}$ and stored at -20 ${ }^{\circ} \mathrm{C}$. Coronal sections $(30 \mu \mathrm{m})$ were cut on a sliding microtome and collected in $0.1 \mathrm{M}$ phosphate buffer.

\section{3. ${ }^{1} \mathrm{H}$ HR-MAS NMR}

All ${ }^{1} \mathrm{H}$ HR-MAS NMR experiments were carried out on a Bruker AVIII $600 \mathrm{MHz}$ NMR spectrometer equipped with a $4 \mathrm{~mm}$ HR-MAS dual inverse ${ }^{1} \mathrm{H} /{ }^{13} \mathrm{C}$ probe with a magic angle gradient. Data were collected with a spinning rate of $6 \mathrm{kHz}$ and a temperature of $277 \mathrm{~K}$. Bruker TOPSPIN 3.1 software was used to acquire and process the NMR data.

The 1 dimensional (1D) ${ }^{1} \mathrm{H}$ HR-MAS NMR spectra were recorded using Carr-Purcell-Meiboom-Gill pulse sequence with water suppression (Maas et al., 1996; Meiboom and Gill, 1958). Each 1D spectrum was acquired applying a spectral width of $12 \mathrm{kHz}$, domain data points $4 \mathrm{k}$, number of averages 128 with an acquisition time of $170 \mathrm{~ms}$, and a relaxation delay of 2 seconds. Since NMR measurements were done on intact brain tissue, the relaxation delay was set to a small value to remove short $\mathrm{T}_{2}$ components due to the presence of lipids. All spectra were processed by an exponential window function corresponding to a line broadening of $1 \mathrm{~Hz}$ and zero-filled prior to Fourier transformation. ${ }^{1} \mathrm{H}$ HR-MAS NMR spectra were phased and baseline corrected using TOPSPIN 3.1. The measurement time (including optimization of NMR parameters and data acquisition) of ${ }^{1} \mathrm{H}$ HR-MAS NMR spectroscopy for each sample was approximately 6 minutes. Two dimensional (2D) homonuclear correlation spectroscopy $\left({ }^{1} \mathrm{H}_{-}{ }^{1} \mathrm{H}\right.$ COSY $)$ and J-resolved 
measurements in magnitude mode were performed using Bruker's standard pulse program library. For parameters used for COSY and J-resolved measurements, see Supplementary Material.

\subsection{MaOB enzymatic activity assay}

Enzymatic activity of MaOB was measured as described previously (Jo et al., 2014). Frozen hippocampus tissues from each mouse were homogenized, and large debris was removed by weak centrifugation. Subsequently, the supernatant was collected, and mitochondria-rich fraction was obtained by centrifuging the supernatant at 13,000 rpm for 20 minutes. The pellet was resuspended in phosphate buffer, and $30 \mu \mathrm{g}$ were used in each well to determine the activity of the MaOB using an Amplex Red Monoamine oxidase Assay Kit (Molecular Probes) according to the manufacturer's instructions. After enzyme reaction, hydrogen peroxide, which is produced by $\mathrm{MaOB}$ activity, is measured by a color change of Amplex red reagent. The color change was quantified by measuring absorbance at $590 \mathrm{~nm}$ with Infinite M200 PRO microplate reader (TECAN).

\subsection{Histology}

To detect $A \beta$ deposition, brain sections ( $30 \mu \mathrm{m}$ thickness) were subjected to immunohistochemistry using the monoclonal $A \beta$ antibody 4G8 (1:2000). Immunolabeling was visualized by using the $A B C$ kit (Vectastain) according to the manufacturer's instructions. Images of the histological sections were obtained using a Leica DM RE HC microscope interfaced to a Leica DC500 3CCD digital camera.

For fluorescent labeling of $A \beta$ deposition using Thioflavin-S (ThS), sections (30 $\mu \mathrm{m}$ thickness) were incubated with $1 \%$ ThS (Sigma) for 20 minutes, followed by 40 minutes incubation in $80 \%$ ethanol and a final rinse in distilled water, dehydrated in toluene, and covered with coverslip using Entellan. For fluorescent immunolabeling, the primary antibodies used were as follows: mouse anti-GFAP (glial fibrillary acidic protein) for labeling of astrocytes (1:1000); rabbit anti-GAD (glutamic acid decarboxylase) antibody for GABAergic neurons (1:4000); rabbit anti-IBA-1 for labeling microglia (1:500); rabbit anti-MaOB (1:100); and mouse antiputrescine (1:50). The mouse brain slices (30 $\mu \mathrm{m}$ thickness) were pretreated with $60 \%$ methanol (30 minutes), followed by washes in $0.1 \mathrm{M}$ tris buffered saline and blocked in tris buffered saline containing $0.3 \%$ Triton $\mathrm{X}-100$ and $5 \%$ goat serum for 30 minutes. Subsequently slices were incubated overnight with primary antibodies. After washing in PBS 3 times, sections were incubated with corresponding fluorescence secondary antibodies (Dianova 1:400) for 1 hour. Confocal laser scanning microscopy (LSM 510, Zeiss, Germany) was performed to reveal colocalization of GFAP/GAD/ThS staining or GFAP/MaOB/ThS or IBA-1/putrescine/ThS. ThS (green fluorescence) was visualized by excitation at $488 \mathrm{~nm}$ and detection of emission at $510 \mathrm{~nm}$ using a low-range band pass (505-530 nm). The Cy3-labeled antigens were visualized using excitation at $543 \mathrm{~nm}$ and emission at $570 \mathrm{~nm}$ and the Cy5 using excitation at $650 \mathrm{~nm}$ and emission at $670 \mathrm{~nm}$. Specificity of primary antibody and immunoreaction was confirmed by omitting primary antibodies or changing probes of the secondary antibodies.

\subsection{Data processing}

\subsubsection{Quantification of metabolites}

All of the spectra were referenced, baseline-, phase-corrected and analyzed by using MestReNova v.8.0 (Mestrelab Research S.L.). Quantification of metabolites was performed by integrating the distinct characteristic signal of GABA with respect to the intensity of total creatine ( $\mathrm{tCr}$ ) resonance using MestReNova (MNOVA). To ensure that only desired region of GABA and $\mathrm{tCr}$ peak from all the spectra is taken into account, line fitting option in the MNOVA were used. Metabolite concentrations ( $\mu \mathrm{mol} / \mathrm{g}$ tissue) were calculated with the formula $C_{x}=\left(A_{x} / A_{T S P}\right) \times\left(9 / n_{x}\right) \times\left(C_{T S P} / M\right)$ with $A_{x}$ and $A_{T S P}$ being the areas under the signals of metabolite $x$ and TSP, 9 and $n_{x}$ the number of protons of TSP and metabolite $x$ evoking the signals, $\mathrm{C}_{\mathrm{TSP}}$ is the concentration of TSP in the sample analyzed (in $\mathrm{nmol}$ ), and $\mathrm{M}$ is the fresh weight $(\mathrm{mg}$ ) of the brain tissue measured. The method was adapted from the previous publications (Lalande et al., 2014; Robert et al., 2011).

\subsubsection{Image analysis of brain sections}

For quantitative histological analysis, the cortex and hippocampus region was outlined according to the "Allen Brain Atlas" with the brain explorer program (http://mouse.brainmap.org) as the reference atlas. The images were exported and further analyzed in Image software (ImageJ, USA). The colors were unmixed by converting the image into 16-bit binary image and then appropriate threshold was applied. After that the stained area was selected and the percentage of the total area was calculated using analyze particles. Any alterations in brightness and contrast were equally applied to the entire image set. The quantification of $A \beta$ plaque load, astrocytes, and GAD was performed, and data were exported to Origin Pro v. 8 software for data analysis. For image coregistration, immunohistological images were matched with each other using common anatomical landmarks such as the ventricles, corpus callosum, and hippocampal fissure.

\subsubsection{Statistical analyses}

All statistical analyses ( $t$-test and analysis of variance) of the NMR and histological quantifications were performed with Origin Pro v.8. The paired and/or unpaired Student's t-test was used to compare mean values. F-values were calculated and F-values larger than $2.8(p<0.05)$ were considered significant. KolmogorovSmirnov normality tests were performed which confirmed that the longitudinal HR-MAS NMR data were normally distributed for a particular age/genotype with a probability ranging from 0.5 to 0.9 . A Kruskal-Wallis 1-way analysis of variance along with rank test was implemented on the NMR data to compare the median of metabolites levels for all group comparisons. This method confirms that samples come from the same population for a particular age, sex, and genotype. Tests for homogeneity of variances between different ages (3, 6, 9, 12, and 18 months) were computed with Origin Pro v. 8. No statistically significant change in variance was observed in particular age for any genotype. Subsequent Mann-Whitney tests were used to make pairwise comparisons between different mice groups. Bonferroni correction for multiple comparisons (20 comparison $=4$ regions $\times 5$ time point) was applied to identify significance of differences among different age groups.

\section{Results}

Alterations in GABA concentrations are associated with several neurological disorders, including AD. Interestingly, previous studies with healthy subjects have shown that women have higher cortical GABA levels than men (Cosgrove et al., 2007). Here, we wanted to address the following research questions: Is the sex-specific difference in GABA uniformly distributed over the brain or more localized to specific regions? How do the levels of GABA change during normal aging? How are sex-specific differences in GABA influenced during AD progression? To find answers to these questions, we applied HR-MAS NMR methods to measure the concentrations of GABA in prefrontal cortex, parietal cortex, hippocampus, and thalamus regions of male and female $\operatorname{Tg} 2576$ mice at the age of 
$3,6,9,12$, and 18 months. In addition, we analyzed the role of astrocytes in GABAergic dysfunction and sex discrimination in AD.

\subsection{Detection of GABA in intact brain tissues}

The development of noninvasive and accurate methods for the measurement of GABA in intact tissues as well as under in vivo conditions using ${ }^{1} \mathrm{H}$ NMR has been an active area of research in the recent years (Ke et al., 2004; O'Gorman et al., 2011). GABA has a complex resonance peak pattern, which extensively overlaps with other more intense resonance peaks. Therefore, noninvasive measurement of GABA in intact tissue using $1 \mathrm{D}^{1} \mathrm{H}$ NMR has been a great challenge (Braakman et al., 2008; Firat et al., 2011). In this work, we applied HR-MAS NMR in 1 and 2 dimension (2D COSY and J-resolved 2D ${ }^{1} \mathrm{H}$ HR-MAS NMR) to accurately resolve the peaks of GABA in intact brain tissues without any extraction, thus measuring GABA in its native environment. Fig. 1 obtained from parietal cortex of WT mice shows that 2-dimensional COSY and ${ }^{1} \mathrm{H}$ J-resolved (JRES) NMR disperses the overlapping resonances into a second dimension, reducing congestion and increasing metabolite specificity. Using HR-MAS NMR method, the concentrations of multiple metabolites were simultaneously determined. Although several brain metabolites have been assigned and quantified (see Supplementary Figs. 1 and 2 and Supplementary Tables 1 and 2), here, we focus on the use of this technique to quantify age- and sexspecific differences in GABA in various brain regions of WT and Tg2576 mice. Four different brain regions were chosen: prefrontal cortex, parietal cortex, hippocampus, and thalamus which represent brain areas characterized by different neuronal cell types, metabolism, and cytoarchitecture and are differently affected by Alzheimer's disease pathology such as deposition of $A \beta$. In addition, to understand the mechanism of sex-specific fluctuations in GABA levels, we also analyzed simultaneously the concentration of excitatory neurotransmitter, glutamate, and cell type-specific markers such as $\mathrm{N}$-acetyl aspartate (NAA) and m-Ins.

\subsection{Age- and sex-dependent changes in GABA levels in WT mice}

In order to evaluate prospective of age- and sex-related differences in GABA in normal aging, we analyzed GABA levels in

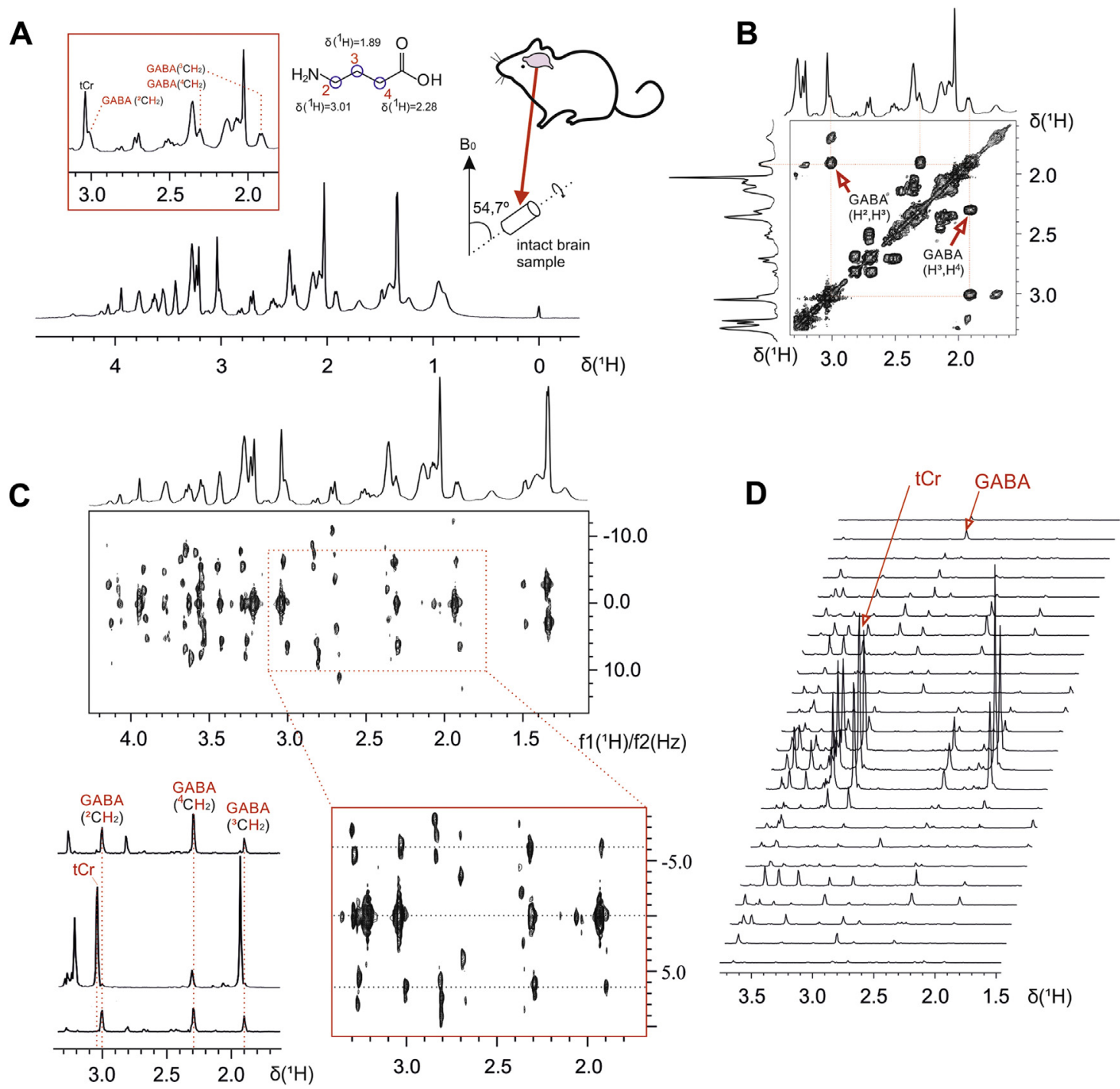

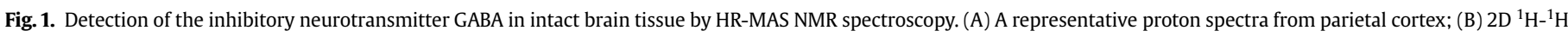

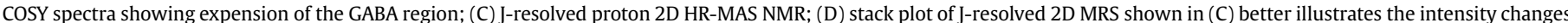

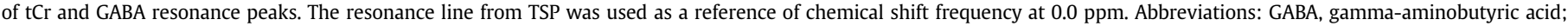

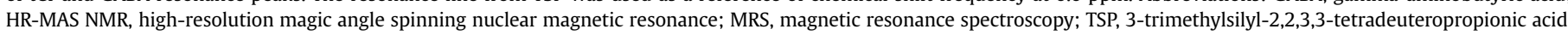


different brain regions in WT mice at the age of $3,6,9,12$, and 18 months.

As illustrated in Fig. 2, in general, in both male and female mice, the level of GABA increased with age in parietal as well as prefrontal cortex from 3 to 9 months of age and then showed a decreasing trend at 12 months of age. Interestingly, female mice consistently showed high levels of GABA in both parietal cortex and prefrontal cortex regions as compared to male mice between 6 and 12 months of age. The high levels of GABA in females as compared to males persisted also at older ages in prefrontal cortex (Fig. 2B). However, in parietal cortex, no significant difference was observed at the age of 18 months (Fig. 2A). The highest sex-specific difference in cortical GABA was seen at the age of 9 months in parietal cortex (Fig. 2A) and at the age of 18 months in prefrontal cortex (Fig. 2B). Taken together, our results show that female mice have significantly higher cortical GABA level as compared to male mice. These results are consistent with previous magnetic resonance spectroscopic studies in humans, which showed that cortical GABA levels in females are higher as compared to healthy male subjects (Sanacora et al., 1999). However, altered sex-specific GABA levels in specific cortical regions with age have not been reported before. Our results show that high levels of cortical GABA exist in female mice as compared to male mice above 6 months of age in both parietal and prefrontal cortex, although in parietal cortex the sex-specific difference disappears at 18 months of age. In prefrontal cortex, the level of GABA remained significantly higher in female than male at 18 months of age.

In hippocampus, the level of GABA shows a consistent increase with age (until 12 months) in both male and female mice and subsequently the level of GABA declines at older age (Fig. 2C). A decline in hippocampal GABA during aging has been previously suggested to be linked to low expression of GAD, an enzyme involved in synthesizing GABA from glutamate (McQuail et al., 2015; Stanley and Shetty, 2004). No sex-specific differences in GABA levels were observed in hippocampus until 9 months of age. However, a significant sex-specific difference in GABA was observed at the age of 12 months, where females have higher GABA as compared to age-matched male mice. Conversely, the sex-specific difference in hippocampal GABA level has been reversed in older mice (18 months), where females have lower GABA levels as compared to aged-matched male mice (Fig. 2C). Interestingly, the GABA/Glu ratio in hippocampus was also lower in female mice (between 12 and 18 months), while, in male mice, such ratio was kept consistent (Fig. 2D).
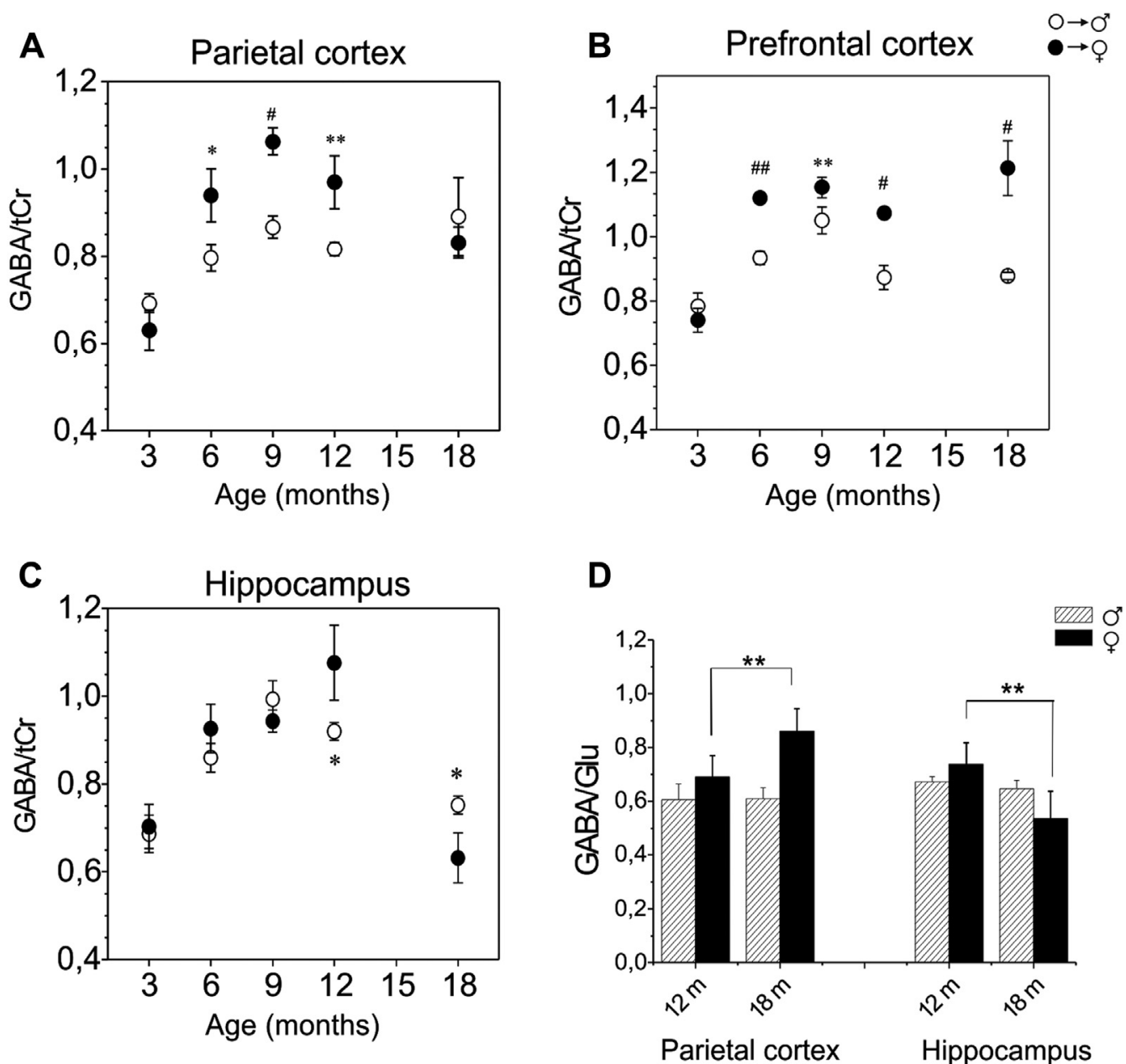

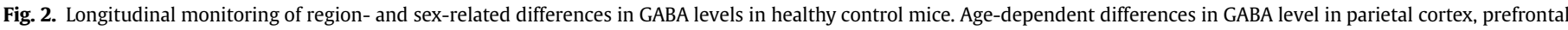

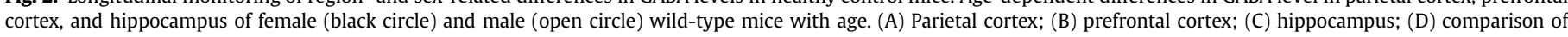

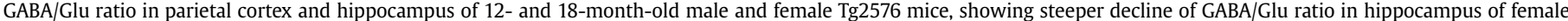

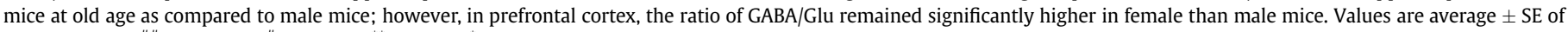
mean $(\mathrm{n}=9)$. $\left({ }^{\# \#} p<0.0001,{ }^{\#} p<0.001,{ }^{* *} p<0.01,{ }^{*} p<0.05\right)$. Abbreviations: GABA, gamma-aminobutyric acid; Glu, glutamate; SE, standard error. 
3.3. Influence of sex on altered GABA level during disease progression

To investigate the apparent GABAergic vulnerability of different brain regions to Alzheimer's disease and to examine the influence of sex on GABA modulation, we performed a longitudinal study to compare GABA levels in parietal cortex, prefrontal cortex, hippocampus, and thalamus regions of transgenic Tg2576 mice and their nontransgenic littermates (WT). Fig. 3 shows systematic longitudinal monitoring of GABA levels relative to $\mathrm{tCr}$ in 4 brain regions of male and female transgenic and WT mice at different ages (3-18 months). The absolute concentration of GABA changes and statistics of all group comparisons are reported in Supplementary Tables 3 and 4 . In the thalamus, no significant differences in GABA levels were observed in transgenic mice as compared to WT mice at all the ages (3-18 months) (Fig. 3D).

Fig. 3 shows longitudinal monitoring of GABA levels in the parietal cortex (Fig. 3A) and the prefrontal cortex (Fig. 3B) of male and female $\operatorname{Tg} 2576$ mice and their nontransgenic littermates. When data of male and female mice were taken together, the level of GABA was marginally lower in transgenic mice as compared to control mice in both parietal cortex as well as in prefrontal cortex. However, the difference between WT and transgenic mice was not statistically significant. Conversely, when the data of male and
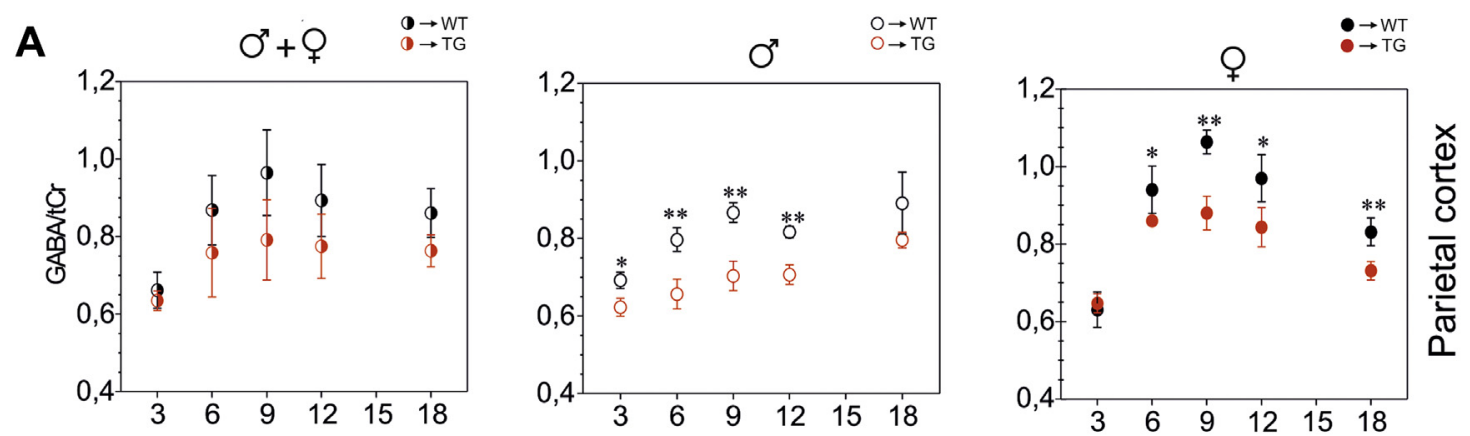

B
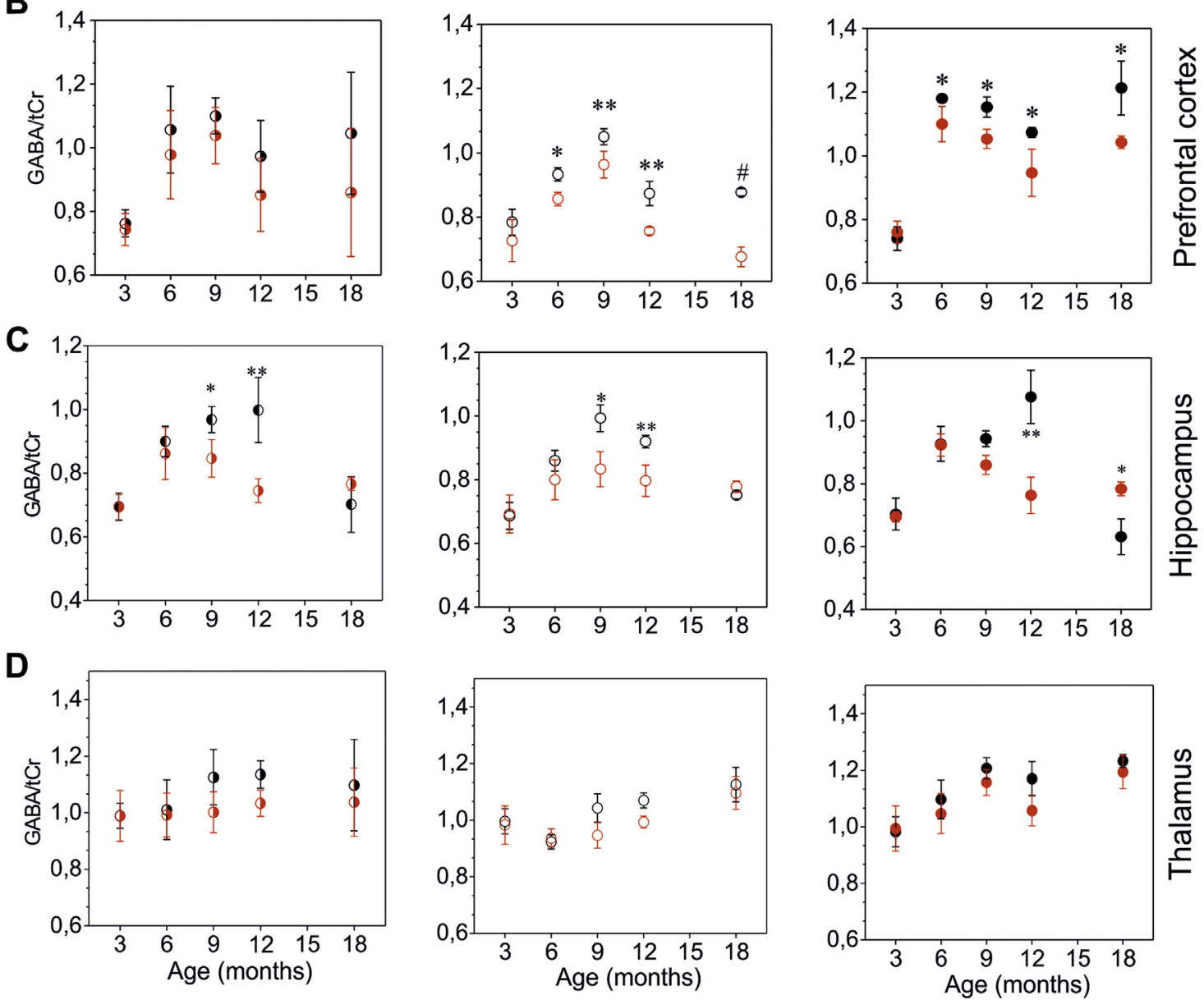

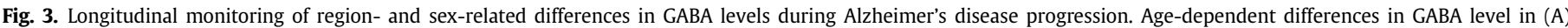

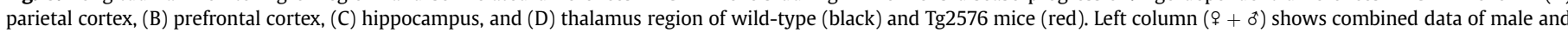

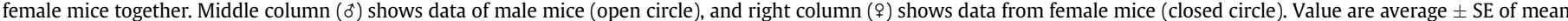

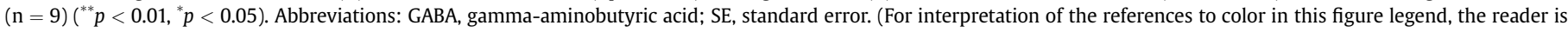
referred to the Web version of this article.) 
female mice were separately evaluated, significantly lower levels of GABA were observed in both parietal cortex (Fig. 3A) and prefrontal cortex (Fig. 3B) of transgenic mice as compared to age-matched control mice.

The influence of sex on GABA decline during aging of $\operatorname{Tg} 2576$ mice was not apparent in the parietal cortex (Fig. 3A). In prefrontal cortex, male Tg2576 mice display very similar levels at 3 and 18 months of age, whereas male WT mice display an increase GABA level between 3 and 18 months. For female mice, both Tg2576 and WT mice display an increase in their prefrontal GABA levels between 3 and 18 months; however, the increase for WT female mice was greater than the 1 for Tg2576 mice (Fig. 3B). Histological analysis of $A \beta$ plaque load in both parietal and prefrontal cortex region has been performed using ThS staining as well as by using polyclonal anti-A $\beta$ 40-42. As shown in Fig. 4, substantially higher plaque load was observed in parietal cortex of female as compared to male mice. However, in prefrontal cortex, no significant sex-specific difference in plaque load was observed. In parallel, we also analyzed the levels of reactive astrocytes by observing the GFAP immunoreactivity (Supplementary Fig. 3). An increase in the GFAP immunoreactivity was observed in both parietal and prefrontal cortex of Tg2576 brain as compared to age-matched control mice. In parietal cortex, the GFAP-positive astrocytes were significantly higher in female mice as compared to male mice especially around amyloid plaques (Supplementary Fig. 3C and D). Comprehensive statistical data of histology for all group comparison is presented in the Supplementary Table 5.

GABA is synthesized in neurons by glutamic acid decarboxylase (GAD), an enzyme involved in synthesizing GABA from glutamate (see Supplementary Fig. 4). Using antibodies against GAD, we analyzed the expression level of GAD in parietal and prefrontal cortex. Significantly lower levels of GAD were observed in both cortex regions of $\mathrm{Tg} 2576$ mice as compared to age-matched WT mice (Fig. 4C-F). These results indicate that low GABA observed in parietal and prefrontal cortex of transgenic mice may be due to its low production via GAD route. The decline in GAD was substantially higher in female as compared to male $\mathrm{Tg} 2576$ mice in parietal cortex, which is inversely correlated with high plaque load in parietal cortex of female as compared to male mice (Fig. $4 \mathrm{E}$ and F).

\subsection{Hippocampal GABA shows dynamic changes during disease progression in $\mathrm{Tg} 2576$ mice}

The influence of sex on hippocampal GABA level during Alzheimer's disease is shown in Fig. 3C. In young adult mice ( 3 and 6 months old), the hippocampal GABA level was not different in transgenic and control mice of both sex. Remarkably, at 9 months of age hippocampal GABA level was significantly lower in male Tg2576
A

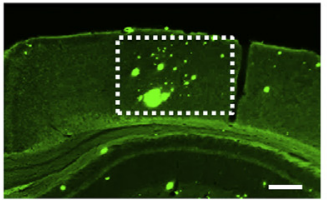

C

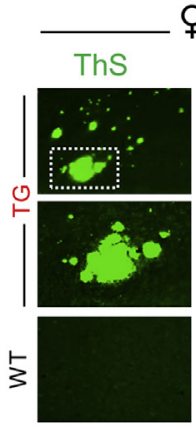

$\mathbf{E}$

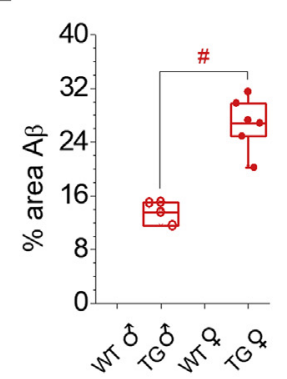

Parietal cortex

要
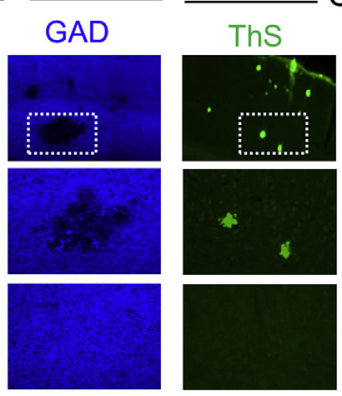

Parietal cortex

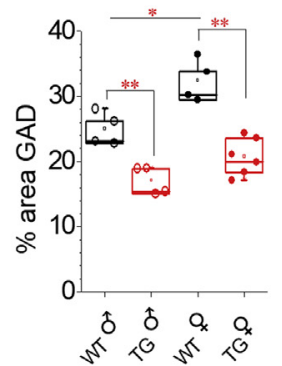

B

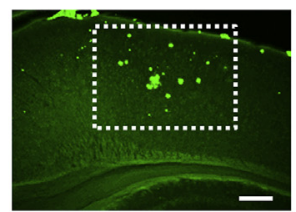

D

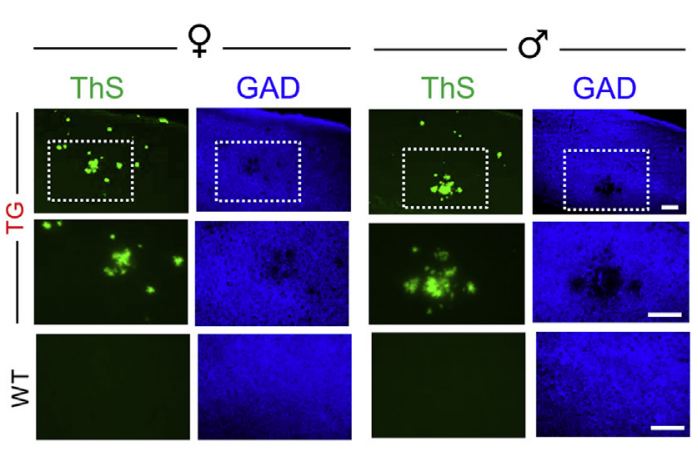

F

Prefrontal cortex

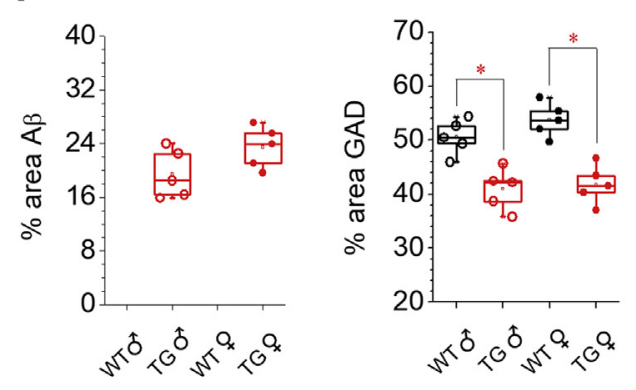

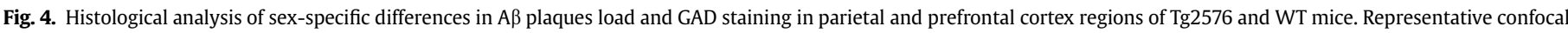

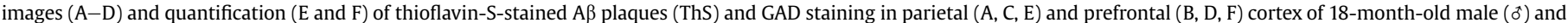

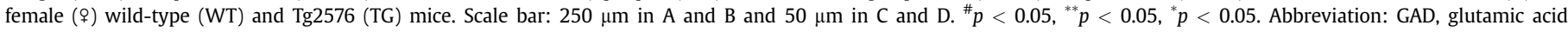
decarboxylase. 
mice as compared to male WT mice (Fig. 3C). On the other hand, at 12 months of age the level of GABA was although lower in both male and female $\operatorname{Tg} 2576$ mice when compared to their respective control mice, the difference in GABA levels between WT and Tg2576 mice was more pronounced in female than male mice (Fig. 3C). Remarkably, at older age (18 months), the hippocampal GABA level was significantly higher in female Tg2576 mice as compared to age-matched control mice (Fig. 3C). A slightly higher hippocampal GABA level was also seen in 18-month-old male Tg2576 mice as compared to age-matched control mice (Fig. 3C). We also examined the levels of reactive astrocytes as well as $A \beta$ plaque deposition in hippocampus region of 18-month-old transgenic and WT mice of both sex (Fig. 5A; Supplementary Figs. 5 and 6). ThS staining showed significantly higher plaque load in female than male mice. As shown in Fig. 5A, numerous reactive astrocytes (GFAP staining) were clustered around the amyloid plaques. Interestingly, the plaque load was especially higher in the stratum lacunosum moleculare and in the dentate gyrus of hippocampus in female transgenic as compared to male transgenic mouse brain.

Next, we examined the expression levels of GAD, which is essential for the production of GABA in GABAergic neurons (Martin and Rimvall, 1993). Interestingly, we found that GAD is minimally expressed in hippocampus of Tg2576 mice especially in the areas surrounding the reactive astrocytes (Fig. 5A; Supplementary Fig. 5). In addition, glutamate, a substrate for GAD was also significantly lower in hippocampus of transgenic mice as compared to age-matched control mice (Fig. 5C). Furthermore, the level of glutamine (Gln) was found to be lower in hippocampus of $\mathrm{Tg} 2576$ mice (Fig. 5C), reflecting a decreased activity of Glu-Gln cycle that operates between astrocytes and neurons (Hertz, 2013; Massucci et al., 2013). The number of activated astrocytes in hippocampus was significantly higher in female transgenic than age-matched male transgenic mice. The cellular microstructural changes in hippocampus of male and female $\operatorname{Tg} 2576$ mice were also confirmed based on analysis of 2 cell type-specific metabolic signatures, namely: NAA and m-Ins. These particular MR-responsive metabolites are specifically compartmentalized within neurons and astrocytes, respectively (Brand et al., 1993). NAA is found almost exclusively in neurons, both in the cell body as well as in neurites and axons (Simmons et al., 1991) and myo-inositol (m-Ins) is predominantly-though likely not exclusively-found in the astrocytic cell body and branches (Brand et al., 1993). Thus, each metabolite can in principle report on a specific cell population's environment. As shown in Fig. 5B, a dramatic increase in the concentration of m-Ins was observed in Tg2576 mice, which was not seen in WT mice. The increase in m-Ins is substantially higher in female than male $\operatorname{Tg} 2576$ mice. In contrast to m-Ins, a reduction in the levels of NAA, was found in transgenic mice than WT mice, and this decline in NAA was more substantial in female than male mice (Fig. 5B) (see Supplementary Table 6 for statistical group comparison). These results suggest significant loss of neuronal integrity and viability as indicated by reduction in NAA and a dramatic increase in the number of reactive astrocytes as reflected by increase in $\mathrm{m}$-Ins at older age in Tg2576 mice and predominantly in female transgenic mice.

\subsection{Increased hippocampal GABA in $\operatorname{Tg} 2576$ mice is produced via $\mathrm{MaOB}$ route}

Besides the GAD route, GABA can also be produced by the degradation of putrescine via MaOB route, as previously reported in the brain and in cultured astrocytes (Jo et al., 2014; Laschet et al., 1992; Yarishkin et al., 2015). MaOB is expressed predominantly in astrocytes and its activity has been shown to be increased in human Alzheimer's disease brain (Saura et al., 1994; Nakamura et al., 1990) as well as in APP/PS1 mice (Jo et al., 2014). MaOB activity was determined in mitochondrial-rich fraction from hippocampus of 12 and 18-month-old male and female WT and Tg2576 mice. As shown
A
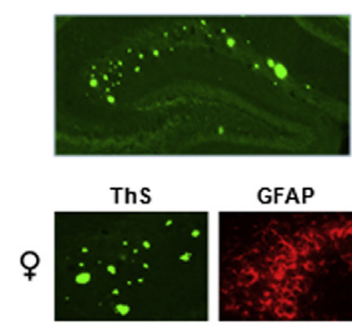

GFAP
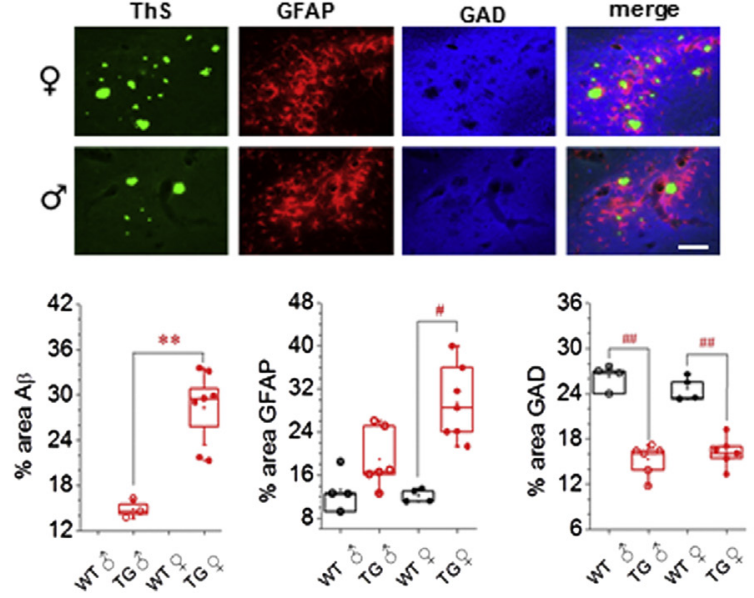

B
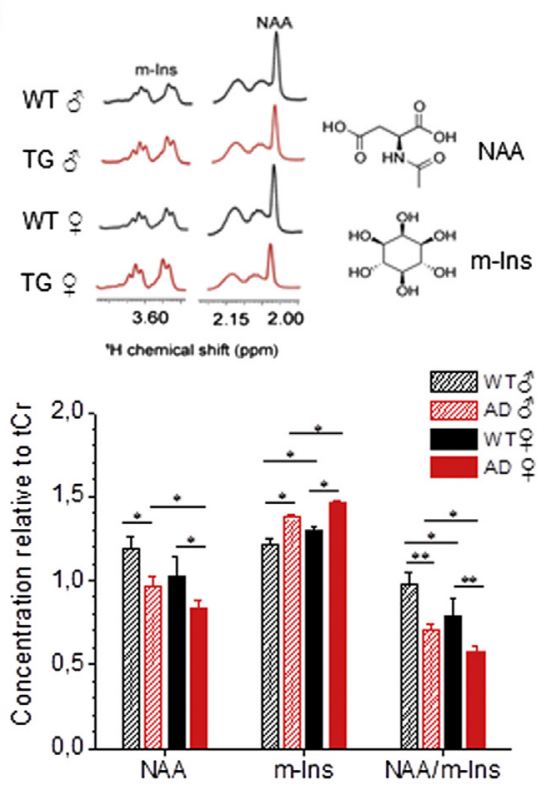
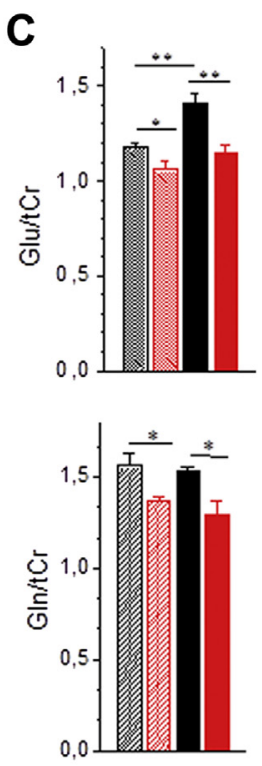

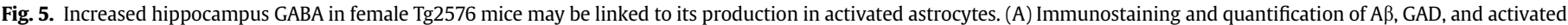

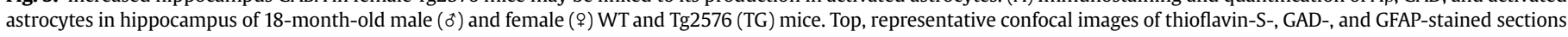

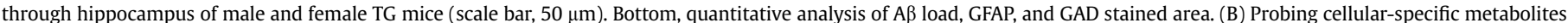

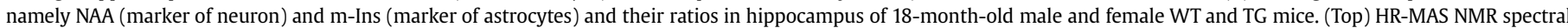

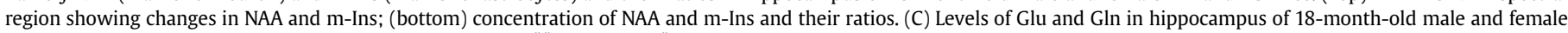

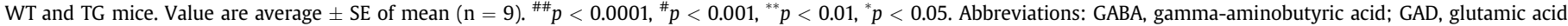

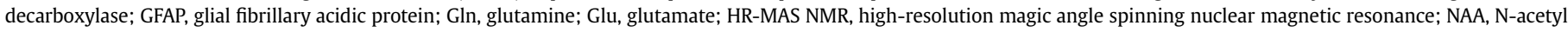
aspartate; SE, standard error. 
in Fig. 6A, MaOB activity was significantly elevated in 18-month-old Tg2576 mice, whereas 12-month-old mice did not show any significant difference in the activity of $\mathrm{MaOB}$ as compared to agematched control mice. These results are in line with the observed increase in hippocampal GABA levels as well as an increased in the number of activated astrocytes surrounding the amyloid plaques which were detected at the age of 18 months and not at 12 months of age. Furthermore, comparison of $\mathrm{MaOB}$ activity in male and female Tg2576 mice showed significantly elevated activity in female mice as compared to male mice (Fig. 6A; Supplementary Table 7). Fig. 6B shows the colocalization of MaOB in GFAP-positive reactive astrocytes. In addition, we found increased immunoreactivity of putrescine in $\operatorname{Tg} 2576$ mice, especially around amyloid plaques (Supplementary Fig. 7). These results clearly indicate that aberrant upregulation of $\mathrm{MaOB}$ in activated astrocytes may be responsible for high levels of hippocampal GABA seen in old Tg2576 mice and more prominently in female $\operatorname{Tg} 2576$ mice.

\section{Discussion}

Age and sex are risk factors of Alzheimer's disease. GABA is a major inhibitory neurotransmitter, involved in essentially all brain circuits (Lehmann et al., 2012; Li et al., 2016). However, the relevance of GABAergic dysfunction in sex discrimination during Alzheimer's disease progression remains unknown. In the present study, we applied HR-MAS NMR and demonstrate that GABA levels undergo dynamic alterations during disease progression in $\mathrm{Tg} 2576$ mice, and its level significantly depends on age, sex, and brain regions.

At first, we have analyzed sex-specific differences in GABA in various brain regions during normal aging (Fig. 2). High levels of cortical GABA were observed at and above 6 months of age in female mice as compared to male. However, at older age the sex-specific difference in GABA vanishes in parietal cortex but becomes larger in prefrontal cortex. In hippocampus, a steeper decline in GABA level was observed in female than male mice between 12 and 18 months of age. Interestingly, the GABA/Glu ratio in hippocampus was also found to be lower in female mice (between 12 and 18 months), while, in male mice, such ratio was kept consistent. These results indicate that disruption of the inhibitory/excitatory balance at old age is prevalent in female brain. In aged females, high GABA in prefrontal cortex, and low in hippocampus as compared to male mice suggests that sex may have an influence on age-related shifts in inhibition of different forms of memory function, that is, hippocampus-dependent spatial reference memory in female and prefrontal cortex-dependent working memory in male mice.

We next followed the influence of sex on altered GABA level during disease progression in the Tg2576 mice (Fig. 3). Significantly lower levels of GABA were observed in both parietal cortex and prefrontal cortex of transgenic mice as compared to age-matched control mice. Remarkably the decline in GABA in both cortex regions of $\operatorname{Tg} 2576$ mice was observed as early as 6 months of age, long before the accumulation of insoluble $A \beta$ into amyloid plaques occurs. The decline in GABA in parietal and prefrontal cortex of young transgenic mice could be attributed to the susceptibility of GABAergic neurons to neurotoxic properties of soluble $A \beta$ oligomer which occur relatively early when compared to other neuronal types in Alzheimer's disease (Krantic et al., 2012; Ono and Yamada, 2011; Ramos et al., 2006). Using the TgCRND8 mouse model, Krantic et al. have argued that $A \beta$ toxicity leads to GABAergic neuron dysfunction before their losses at a later stage (Krantic et al., 2012). In postmortem human studies, a quantitative loss of neurons in the cerebral cortex as well as GABA has been reported (Seidl et al., 2001). The influence of sex on the GABA decline during aging of $\operatorname{Tg} 2576$ mice was not apparent in parietal cortex region (Fig. 3A). However, prefrontal cortex GABA levels were more significantly reduced in old male $\mathrm{Tg} 2576$ mice (18 months old) as compared to age-matched female Tg2576 mice (Fig. 3B). In old Tg2576 mice, a low level of GAD was observed in both cortex regions as compared to control mice (Fig. 4), indicating that low GABA observed in parietal and prefrontal cortex of transgenic mice may be due to its low production via GAD route.

Interestingly, in hippocampus, the time course of GABA levels shows dynamic changes and exhibits significant sex-specific differences as disease progressed (Fig. 3C). At young age (9 months), hippocampal GABA level declined in male but not in female Tg2576 mice. These results indicate that young females may be protected at preplaque stage against aspects of $A \beta$ oligomer toxicity and mitochondrial dysfunction due to the protective effects of estrogen, as has been proposed in earlier studies (Lloret et al., 2008; Nilsen et al., 2006). Interestingly, at 12 months of age, the decline in GABA, although observed in both male and female mice, was more pronounced in female mice than male mice. The onset of reproductive senescence in female Tg2576 mice starts around 12 months of age which also coincides with the start of senile plaques formation as well as the decline in circulating estrogen (Callahan et al., 2001; Zheng et al., 2002). Previous in vivo studies in Tg2576 mice have shown that estrogen depletion leads to the accumulation of $A \beta$ in the CNS, which can be reversed through replacement of estradiol (Zheng et al., 2002). Taken together, our results of a significant decrease in GABA in females at 12 months of age as compared to control mice indicate that low levels of estrogen may be responsible for significant decline in GABAergic neurotransmission.

Remarkably at older age, hippocampal GABA increased significantly in $\mathrm{Tg} 2576$ mice as compared to age-matched control mice,
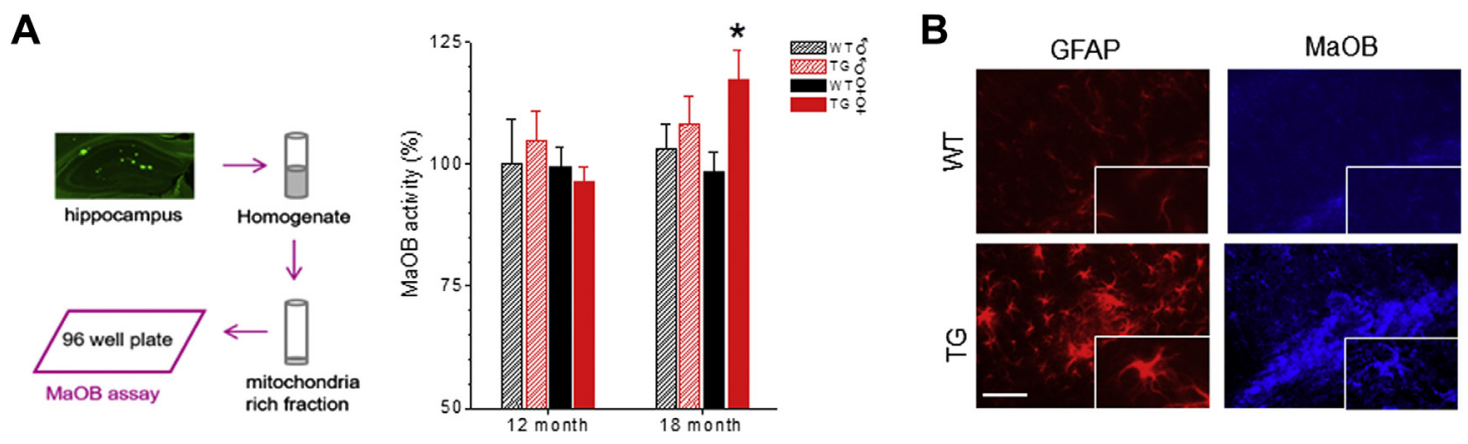

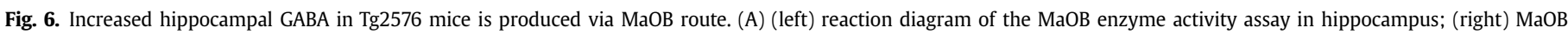

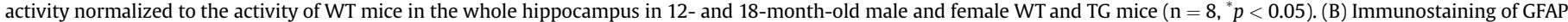

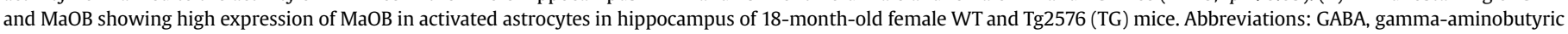
acid; GFAP, glial fibrillary acidic protein. 
and this increase was more pronounced in female $\operatorname{Tg} 2576$ mice. Furthermore, we found significantly high number of $A \beta$ plaque in female than male $\operatorname{Tg} 2576$ mice, especially in the stratum lacunosum moleculare and in the dentate gyrus of hippocampus. The dentate gyrus is known as the principal gateway of cortical input to the hippocampus and is critical for the formation and recall of memory (Kesner, 2007; Nakashiba et al., 2012), and the stratum lacunosum moleculare hosts a strong feed-forward inhibitory network composed of various types of GABAergic interneurons (Freund and Buzsáki, 1996). Thus, amyloid pathology in these regions can have significant impact on memory impairment. To analyze whether increased level of GABA in the hippocampus of old Tg2576 mice is due to its elevated production, we examined the expression levels of GAD, which is essential for the production of GABA in GABAergic neurons (Martin and Rimvall, 1993). Interestingly, we found that GAD expression was very low in hippocampus of $\operatorname{Tg} 2576$ mice especially in the areas surrounding the $A \beta$ plaque (Fig. $5 A$ ). These results indicate that high hippocampal GABA seen in old transgenic mice may not be due to high glutamate to GABA conversion catalyzed by GAD.

Recent studies in another Alzheimer's disease mouse model (APP/PS1) show an increase in hippocampal GABA levels which was demonstrated to be due to increased production of GABA from putrescine in reactive astrocytes (Jo et al., 2014). It has been proposed that an abnormal increase in tonic GABA release from reactive astrocytes in the hippocampus may be directly responsible for the memory impairment in Alzheimer's disease. In this study, we observed that $\operatorname{Tg} 2576$ mice have also significantly high number of activated astrocytes in hippocampus, and this number is higher in female than male Tg2576 mice. Therefore, we hypothesized that in female $\operatorname{Tg} 2576$ mice high GABA levels in hippocampus may be linked to high GABA production in astrocytes. To assess this possibility, we examined the activity of $\mathrm{MaOB}$, a key enzyme involved in the conversion of putrescine to GABA, and is predominantly expressed in astrocytes (Nakamura et al., 1990; Saura et al., 1994). The MaOB activity was significantly elevated in old Tg2576 mice and more elevated in female than male Tg2576 mice (Fig. 6A). The expression of MaOB was clearly elevated in activated astrocytes in hippocampus (Fig. 6B). These results suggest that the upregulation of $\mathrm{MaOB}$ in activated astrocytes may be responsible for high level of GABA seen in hippocampus of old $\mathrm{Tg} 2576$ mice and more significantly in female Tg2576 mice. Taken together, these results indicate that an abnormal increase in tonic GABA release from reactive astrocytes in the hippocampus may be responsible for memory impairment in old $\operatorname{Tg} 2576$ mice.

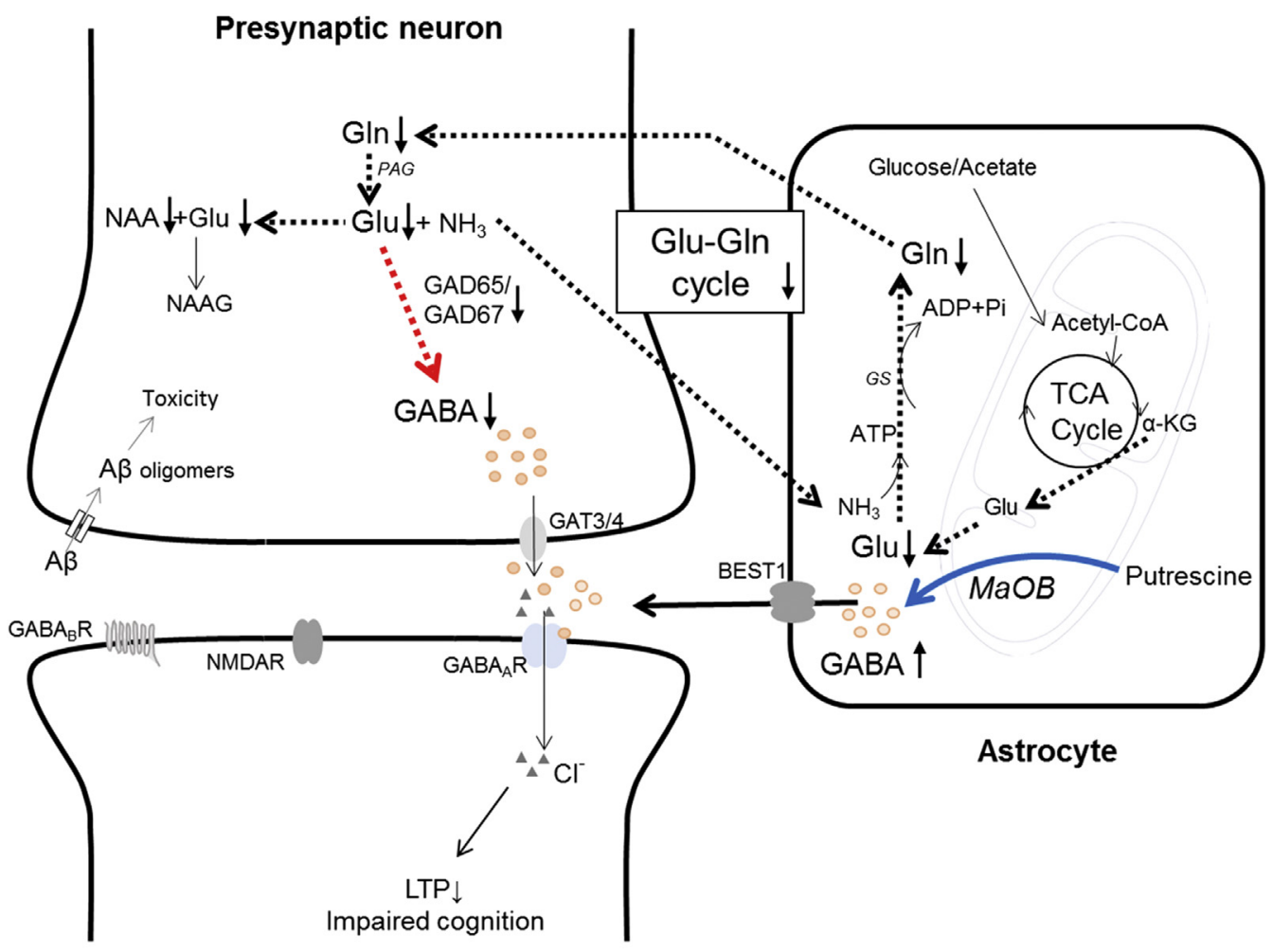

Postsynaptic neuron

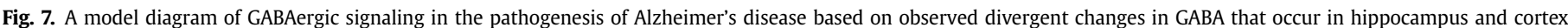

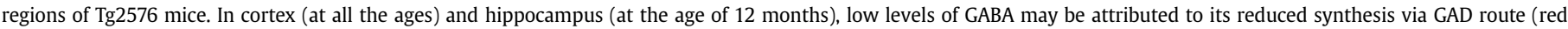

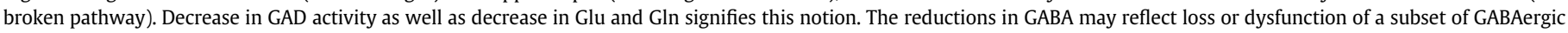

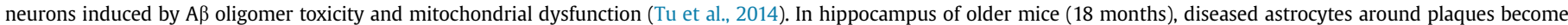

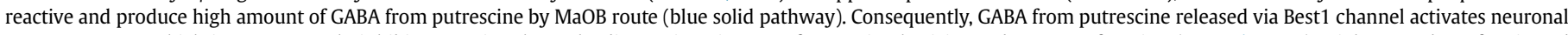

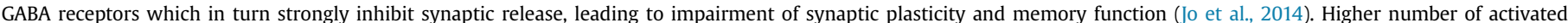

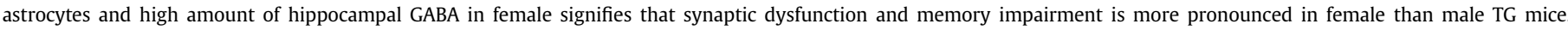

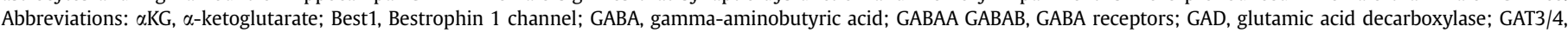

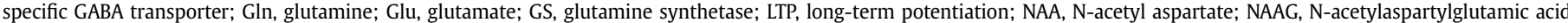

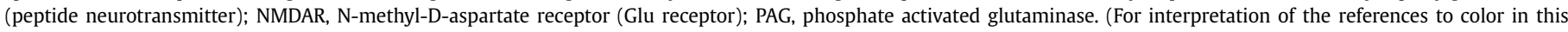
figure legend, the reader is referred to the Web version of this article.) 
A model diagram of GABAergic signaling in the pathogenesis of Alzheimer's disease based on our observation of divergent changes in GABA that occur in hippocampus and cortex regions of $\mathrm{Tg} 2576$ mice is shown in Fig. 7. In cortex (at all the ages) and hippocampus (at the age of 12 months), low levels of GABA may be attributed to its reduced synthesis via GAD route. A decrease in GAD activity as well as decreases in Glu and Gln signifies this notion. The reductions in GABA may reflect loss or dysfunction of a subset of GABAergic neurons induced by $A \beta$ oligomer toxicity and mitochondrial dysfunction (Moreira et al., 2010; Reddy and Beal, 2008; Tu et al., 2014). In the hippocampus of older mice (18 months), astrocytes around plaques become reactive and produce high amount of GABA from putrescine by MaOB route. Consequently, GABA released via the Best1 channel activates neuronal GABA receptors, which in turn strongly inhibit synaptic release, leading to impairment of synaptic plasticity and memory function as also has been confirmed in another mouse model (APP/PS1) (Jo et al., 2014). The higher number of activated astrocytes and high amounts of hippocampal GABA in females signify that synaptic dysfunction and memory impairment are more pronounced in females that can be at the root of marked sex disparities observed in Alzheimer's disease incidence.

Taken together, our results demonstrate that GABA levels undergo dynamic alterations during diseased progression in Tg2576 mice, and its level significantly depends on age, sex, and brain regions. The influence of sex on GABA levels that occur during Alzheimer's disease in aged hippocampus and prefrontal cortex offer unique challenges from the perspective of treating memory decline. Based on the mechanistic data described previously, therapeutics that target inhibitory changes in 1 brain region might be expected to exacerbate age-related dysregulation of GABAergic signaling in another. Thus, different therapeutic strategies may be required for improving memory functions supported by the hippocampus and prefrontal cortex.

\section{Disclosure statement}

The authors report no disclosures or conflicts of interest relevant to the current work.

\section{Acknowledgements}

This work was supported by grants from Alzheimer Forschung Initiative e.V. (AFI, Grant $\mathrm{Nr}$ 13810). The authors are grateful to $\mathrm{Dr}$ Karen Hsiao Ashe (University of Minnesota, USA) for providing the initial three Tg2576 F1 mice for further breeding. They thank Dr Holger Scheidt for technical help during HR-MAS NMR measurements.

\section{Appendix A. Supplementary data}

Supplementary data associated with this article can be found, in the online version, at https://doi.org/10.1016/j.neurobiolaging.2017. 10.015 .

\section{References}

Bareggi, S.R., Franceschi, M., Bonini, L., Zecca, L., Smirne, S., 1982. Decreased csf concentrations of homovanillic acid and $\gamma$-aminobutyric acid in Alzheimer's disease: age- or disease-related modifications? Arch. Neurol. 39, 709-712.

Braakman, N., Oerther, T., de Groot, H.J.M., Alia, A., 2008. High resolution localized two-dimensional MR spectroscopy in mouse brain in vivo. Magn. Reson. Med. $60,449-456$.

Brand, A., Richter-Landsberg, C., Leibfritz, D., 1993. Multinuclear NMR studies on the energy metabolism of glial and neuronal cells. Dev. Neurosci. 15, 289-298.
Callahan, M.J., Lipinski, W.J., Bian, F., Durham, R.A., Pack, A., Walker, L.C., 2001 Augmented senile plaque load in aged female $\beta$-amyloid precursor proteintransgenic mice. Am. J. Pathol. 158, 1173-1177.

Canter, R.G., Penney, J., Tsai, L.H., 2016. The road to restoring neural circuits for the treatment of Alzheimer's disease. Nature 539, 187-196.

Carter, C.L., Resnick, E.M., Mallampalli, M., Kalbarczyk, A., 2012. Sex and gender differences in Alzheimer's disease: recommendations for future research. J. Womens Health (Larchmt) 21, 1018-1023.

Corder, E.H., Ghebremedhin, E., Taylor, M.G., Thal, D.R., Ohm, T.G., Braak, H., 2004 The biphasic relationship between regional brain senile plaque and neurofibrillary tangle distributions: modification by age, sex, and APOE polymorphism. Ann. N.Y. Acad. Sci. 1019, 24-28.

Cosgrove, K.P., Mazure, C.M., Staley, J.K., 2007. Evolving knowledge of sex differences in brain structure, function and chemistry. Biol. Psychiatry 62, 847-855.

Davis, A.M., Ward, S.C., Selmanoff, M., Herbison, A.E., McCarthy, M.M., 1999 Developmental sex differences in amino acid neurotransmitter levels in hypothalamic and limbic areas of rat brain. Neuroscience 90, 1471-1482.

Dulla, C.G., Coulter, D.A., Ziburkus, J., 2016. From molecular circuit dysfunction to disease: case studies in epilepsy, traumatic brain injury, and Alzheimer's disease. Neuroscientist 22, 295-312.

Firat, K., Niels, B., Mark, A.V.B., Huub, J.M.D.G., Alia, A., 2011. Prospects of magnetic resonance spectroscopy in mouse models of Alzheimers disease. Curr. Med. Imag. Rev. 7, 80-87.

Freund, T.F., Buzsáki, G., 1996. Interneurons of the hippocampus. Hippocampus 6 , $347-470$.

Grouselle, D., Winsky-Sommerer, R., David, J.P., Delacourte, A., Dournaud, P. Epelbaum, J., 1998. Loss of somatostatin-like immunoreactivity in the frontal cortex of Alzheimer patients carrying the apolipoprotein epsilon 4 allele. Neurosci. Lett. 255, 21-24.

Gueli, M.C., Taibi, G., 2013. Alzheimer's disease: amino acid levels and brain metabolic status. Neurol. Sci. 34, 1575-1579.

Hertz, L., 2013. The glutamate-glutamine (GABA) cycle: importance of late postnatal development and potential reciprocal interactions between biosynthesis and degradation. Front. Endocrinol. 4, 59-74.

Hsiao, K., Chapman, P., Nilsen, S., Eckman, C., Harigaya, Y., Younkin, S., Yang, F., Cole, G., 1996. Correlative memory deficits, A $\beta$ elevation, and amyloid plaques in transgenic mice. Science 274, 99-103.

Jo, S., Yarishkin, O., Hwang, Y.J., Chun, Y.E., Park, M., Woo, D.H., Bae, J.Y., Kim, T. Lee, J., Chun, H., Park, H.J., Lee, D.Y., Hong, J., Kim, H.Y., Oh, S.-J., Park, S.J., Lee, H., Yoon, B.-E., Kim, Y., Jeong, Y., Shim, I., Bae, Y.C., Cho, J., Kowall, N.W., Ryu, H. Hwang, E., Kim, D., Lee, C.J., 2014. GABA from reactive astrocytes impairs memory in mouse models of Alzheimer's disease. Nat. Med. 20, 886-896.

Jucker, M., Walker, L.C., 2011. Pathogenic protein seeding in Alzheimer's disease and other neurodegenerative disorders. Ann. Neurol. 70, 532-540.

Ke, Y., Streeter, C.C., Nassar, L.E., Sarid-Segal, O., Hennen, J., Yurgelun-Todd, D.A. Awad, L.A., Rendall, M.J., Gruber, S.A., Nason, A., Mudrick, M.J., Blank, S.R. Meyer, A.A., Knapp, C., Ciraulo, D.A., Renshaw, P.F., 2004. Frontal lobe GABA levels in cocaine dependence: a two-dimensional, J-resolved magnetic resonance spectroscopy study. Psychiatry Res. 130, 283-293.

Kesner, R.P., 2007. A behavioral analysis of dentate gyrus function. Prog. Brain Res. $163,567-576$.

Kobayashi, D.T., Chen, K.S., 2005. Behavioral phenotypes of amyloid-based genetically modified mouse models of Alzheimer's disease. Genes Brain Behav. 4, 173-196.

Krantic, S., Isorce, N., Mechawar, N., Davoli, M.A., Vignault, E., Albuquerque, M., Chabot, J.G., Moyse, E., Chauvin, J.P., Aubert, I., McLaurin, J., Quirion, R., 2012. Hippocampal GABAergic neurons are susceptible to amyloid- $\beta$ toxicity in vitro and are decreased in number in the Alzheimer's disease TgCRND8 mouse model. J. Alzheimers. Dis. 29, 293-308.

Lalande, J., Halley, H., Balayssac, S., Gilard, V., Déjean, S., Martino, R., Francés, B. Lassalle, J.M., Malet-Martino, M., 2014. ${ }^{1}$ H NMR metabolomic signatures in five brain regions of the AßPPswe Tg2576 mouse model of Alzheimer's disease at four ages. J. Alzheimers. Dis. 39, 121-143.

Laschet, J., Grisar, T., Bureau, M., Guillaume, D., 1992. Characteristics of putrescine uptake and subsequent GABA formation in primary cultured astrocytes from normal C57BL/6J and epileptic DBA/2J mouse brain cortices. Neuroscience 48 $151-157$.

Lehmann, K., Steinecke, A., Bolz, J., 2012. GABA through the ages: regulation of cortical function and plasticity by inhibitory interneurons. Neural Plast. 2012, $1-11$.

Li, Y., Sun, H., Chen, Z., Xu, H., Bu, G., Zheng, H., 2016. Implications of GABAergic neurotransmission in Alzheimer's disease. Front. Aging Neurosci. 8, 31-42.

Lloret, A., Badía, M.-C., Mora, N.J., Ortega, A., Pallardó, F.V., Alonso, M.-D., Atamna, H., Viña, J., 2008. Gender and age-dependent differences in the mitochondrial apoptogenic pathway in Alzheimer's disease. Free Radic. Biol. Med. 44 2019-2025.

Lowe, S.L., Francis, P.T., Procter, A.W., Palmer, A.M., Davison, A.N., Bowen, D.M., 1988 Gamma-aminobutyric acid concentration in brain tissue at two stages of Alzheimer's disease. Brain 111, 785-799.

Maas, W.E., Laukien, F.H., Cory, D.G., 1996. Gradient, high resolution, magic angle sample spinning nmr. J. Am. Chem. Soc. 118, 13085-13086.

Martin, D.L., Rimvall, K., 1993. Regulation of $\gamma$-aminobutyric acid synthesis in the brain. J. Neurochem. 60, 395-407. 
Massucci, F.A., DiNuzzo, M., Giove, F., Maraviglia, B., Castillo, I.P., Marinari, E., Martino, A.D., 2013. Energy metabolism and glutamate-glutamine cycle in the brain: a stoichiometric modeling perspective. BMC Syst. Biol. 7, 103-116.

McQuail, J.A., Frazier, C.J., Bizon, J.L., 2015. Molecular aspects of age-related cognitive decline: the role of GABA signaling. Trends Mol. Med. 21, 450-460.

Meiboom, S., Gill, D., 1958. Modified spin-echo method for measuring nuclear relaxation times. Rev. Sci. Instrum. 29, 688-691.

Moreira, P.I., Carvalho, C., Zhu, X., Smith, M.A., Perry, G., 2010. Mitochondrial dysfunction is a trigger of Alzheimer's disease pathophysiology. Biochim. Biophys. Acta 1802, 2-10.

Musicco, M., 2009. Gender differences in the occurrence of Alzheimer's disease. Funct. Neurol. 24, 89-92.

Nakamura, S., Kawamata, T., Akiguchi, I., Kameyama, M., Nakamura, N., Kimura, H., 1990. Expression of monoamine oxidase B activity in astrocytes of senile plaques. Acta Neuropathol. 80, 419-425.

Nakashiba, T., Cushman, J.D., Pelkey, K.A., Renaudineau, S., Buhl, D.L., McHugh, T.J., Barrera, V.R. Chittajallu, R. Iwamoto, K.S., McBain, C.J., Fanselow, M.S., Tonegawa, S., 2012. Young dentate granule cells mediate pattern separation, whereas old granule cells facilitate pattern completion. Cell 149, 188-201.

Nilsen, J., Morales, A., Brinton, R.D., 2006. Medroxyprogesterone acetate exacerbates glutamate excitotoxicity. Gynecol. Endocrinol. 22, 355-361.

Nilsen, L.H., Melø, T.M., Witter, M.P., Sonnewald, U., 2014a. Early differences in dorsal hippocampal metabolite levels in males but not females in a transgenic rat model of Alzheimer's disease. Neurochem. Res. 39, 305-312.

Nilsen, L.H., Witter, M.P., Sonnewald, U., 2014b. Neuronal and astrocytic metabolism in a transgenic rat model of Alzheimer's disease. J. Cereb. Blood Flow Metab. 34, 906-914.

O’Gorman, R.L., Michels, L., Edden, R.A., Murdoch, J.B., Martin, E., 2011. In Vivo Detection of GABA and glutamate with MEGA-PRESS: reproducibility and gender effects. J. Magn. Reson. Imaging 33, 1262-1267.

Ono, K., Yamada, M., 2011. Low-n oligomers as therapeutic targets of Alzheimer's disease. J. Neurochem. 117, 19-28.

Pike, C.J., Cotman, C.W., 1993. Cultured GABA-immunoreactive neurons are resistant to toxicity induced by $\beta$-amyloid. Neuroscience $56,269-274$.

Price, J.L., Davis, P.B., Morris, J.C., White, D.L., 1991. The distribution of tangles, plaques and related immunohistochemical markers in healthy aging and Alzheimer's disease. Neurobiol. Aging 12, 295-312.

Ramos, B., Baglietto-Vargas, D., Rio, J.C.D., Moreno-Gonzalez, I., Santa-Maria, C., Jimenez, S., Caballero, C., Lopez-Tellez, J.F., Khan, Z.U., Ruano, D., Gutierrez, A., Vitorica, J., 2006. Early neuropathology of somatostatin/NPY GABAergic cells in the hippocampus of a PS1 $\times$ APP transgenic model of Alzheimer's disease. Neurobiol. Aging 27, 1658-1672.

Reddy, P.H., Beal, M.F., 2008. Amyloid beta, mitochondrial dysfunction and synaptic damage: implications for cognitive decline in aging and Alzheimer's disease. Trends Mol. Med. 14, 45-53.

Robert, O., Sabatier, J., Desoubzdanne, D., Lalande, J., Balayssac, S., Gilard, V., Martino, R., Malet-Martino, M., 2011. pH optimization for a reliable quantification of brain tumor cell and tissue extracts with ${ }^{1} \mathrm{H}$ NMR: focus on cholinecontaining compounds and taurine. Anal. Bioanal. Chem. 399, 987-999.

Rossor, M.N., Garrett, N.J., Johnson, A.L., Mountjoy, C.Q., Roth, M., Iversen, L.L., 1982. A post-mortem study of the cholinergic and gaba systems in senile dementia. Brain 105, 313-330.

Samakashvili, S., Ibáñez, C., Simó, C., Gil-Bea, F.J., Winblad, B., Cedazo-Mínguez, A., Cifuentes, A., 2011. Analysis of chiral amino acids in cerebrospinal fluid samples linked to different stages of Alzheimer disease. Electrophoresis 32, 2757-2764.
Sanacora, G., Mason, G.F., Rothman, D.L., Behar, K.L., Hyder, F., Petroff, O.A. Berman, R.M., Charney, D.S., Krystal, J.H., 1999. Reduced cortical $\gamma$-aminobutyric acid levels in depressed patients determined by proton magnetic resonance spectroscopy. Arch. Gen. Psychiatry 56, 1043-1047.

Saura, J., Luque, J.M., Cesura, A.M., Da Prada, M., Chan-Palay, V., Huber, G., Löffler, J. Gray, J., Richards, J.G., 1994. Increased activity of monoamine oxidase-B in plaque-associated astrocytes in Alzheimer brain demonstrated by quantitative enzyme autoradiography using ${ }^{3} \mathrm{H}$-lazabemide. Neurobiol. Aging 15 S120-S121.

Seidl, R., Cairns, N., Singewald, N., Kaehler, S.T., Lubec, G., 2001. Differences between GABA levels in Alzheimer's disease and Down syndrome with Alzheimer-like neuropathology. Naunyn Schmiedebergs Arch. Pharmacol. 363, 139-145.

Simmons, M.L., Frondoza, C.G., Coyle, J.T., 1991. Immunocytochemical localization of $\mathrm{N}$-acetyl-aspartate with monoclonal antibodies. Neuroscience 45, 37-45.

Spillane, J.A., White, P., Goodhardt, M.J., Flack, R.H.A., Bowen, D.M., Davison, A.N. 1977. Selective vulnerability of neurones in organic dementia. Nature 266 $558-559$.

Stanley, D.P., Shetty, A.K., 2004. Aging in the rat hippocampus is associated with widespread reductions in the number of glutamate decarboxylase-67 positive interneurons but not interneuron degeneration. J. Neurochem. 89, 204-216.

Sun, B., Halabisky, B., Zhou, Y., Palop, J.J., Yu, G., Mucke, L., Gan, L., 2009. Imbalance between GABAergic and glutamatergic transmission impairs adult neurogenesis in an animal model of Alzheimer's disease. Cell Stem Cell 5, 624-633.

Takahashi, H., Brasnjevic, I., Rutten, B.P.F, Van Der Kolk, N., Perl, D.P., Bouras, C., Steinbusch, H.W.M., Schmitz, C., Hof, P.R., Dickstein, D.L., 2010. Hippocampal interneuron loss in an APP/PS1 double mutant mouse and in Alzheimer's disease. Brain Struct. Func. 214, 145-160.

Takeuchi, A., Irizarry, M.C., Duff, K., Saido, T.C., Hsiao Ashe, K., Hasegawa, M., Mann, D.M.A., Hyman, B.T., Iwatsubo, T., 2000. Age-related amyloid beta deposition in transgenic mice overexpressing both Alzheimer mutant presenilin 1 and amyloid beta precursor protein Swedish mutant is not associated with global neuronal loss. Am. J. Pathol. 157, 331-339.

Terry, R.D., Masliah, E., Salmon, D.P., Butters, N., DeTeresa, R., Hill, R., Hansen, L.A. Katzman, R., 1991. Physical basis of cognitive alterations in Alzheimer's disease: synapse loss is the major correlate of cognitive impairment. Ann. Neurol. 30, 572-580.

Tu, S., Okamoto, S.-I., Lipton, S.A., Xu, H., 2014. Oligomeric Aß-induced synaptic dysfunction in Alzheimer's disease. Mol. Neurodegener. 9, 48.

van Duijn, S., Nabuurs, R.J., van Duinen, S.G., Natté, R., van Buchem, M.A., Alia, A. 2013. Longitudinal monitoring of sex-related in vivo metabolic changes in the brain of Alzheimer's disease transgenic mouse using magnetic resonance spectroscopy. J. Alzheimers Dis. 34, 1051-1059.

Viña, J., Lloret, A., 2010. Why women have more Alzheimer's disease than men: gender and mitochondrial toxicity of amyloid-beta peptide. J. Alzheimers Dis 20, 527-533.

Yarishkin, O., Lee, J., Jo, S., Hwang, E.M., Lee, C.J., 2015. Disinhibitory action of astrocytic GABA at the perforant path to dentate gyrus granule neuron synapse reverses to inhibitory in Alzheimer's disease model. Exp. Neurobiol. 24 211-218.

Zheng, H., Xu, H., Uljon, S.N., Gross, R., Hardy, K., Gaynor, J., Lafrancois, J. Simpkins, J., Refolo, L.M., Petanceska, S., Wang, R., Duff, K., 2002. Modulation of A $\beta$ peptides by estrogen in mouse models. J. Neurochem. 80, 191-196.

Zimmer, R., Teelken, A.W., Trieling, W.B., Weber, W., Weihmayr, T., Lauter, H., 1984 $\Gamma$-aminobutyric acid and homovanillic acid concentration in the csf of patients with senile dementia of Alzheimer's type. Arch. Neurol. 41, 602-604. 